\title{
Integrating pharmaceutical systems strengthening in the current global health scenario: three 'uncomfortable truths'
}

\author{
Tamara Hafner ${ }^{1}$, Marlon Banda², Jillian Kohler ${ }^{3}$, Zaheer-Ud-Din Babar ${ }^{4}$, Murray Lumpkin ${ }^{5}$, \\ Mojisola Christianah Adeyeye ${ }^{6}$, Emmanuel Nfor ${ }^{1}$, Francis Aboagye-Nyame ${ }^{1}$ and Javier Guzman ${ }^{1 *}$
}

\begin{abstract}
The response to emergency public health challenges such as HIV, TB, and malaria has been successful in mobilising resources and scaling up treatment for communicable diseases. However, many of the remaining challenges in improving access to and appropriate use of medicines and services require pharmaceutical systems strengthening. Incorporating pharmaceutical systems strengthening into global health programmes requires recognition of a few 'truths'. Systems strengthening is a lengthy and resource-intensive process that requires sustained engagement, which may not align with the short time frame for achieving targets in vertical-oriented programmes. Further, there is a lack of clarity on what key metrics associated with population and patient level outcomes should be tracked for systems strengthening interventions. This can hinder advocacy and communication with decision makers regarding health systems investments. Moving forward, it is important to find ways to balance the inherent tensions between the short-term focus on the efficiency of vertical programmes and broader, longer-term health and development objectives. Global health programme design should also shift away from a narrow view of medicines primarily as an input commodity to a more comprehensive view that recognizes the various structures and processes and their interactions within the broader health system that help ensure access to and appropriate use of medicines and related services.
\end{abstract}

Keywords: Pharmaceutical systems strengthening, Access to medicines

\section{Introduction}

Low- and middle-income countries (LMICs) are undergoing a triple transition that involves a shift from development assistance to domestic resources, an epidemiological transition from communicable to noncommunicable diseases as the major source of morbidity and mortality, and a reorganisation of national health systems to meet universal health coverage (UHC) goals as expressed in Target 3.8 of the Sustainable Development Goals (SDGs) [1]. Noncommunicable diseases such as cancer, strokes,

\footnotetext{
* Correspondence: jguzman@mtapsprogram.org

'USAID Medicines, Technologies, and Pharmaceutical Services (MTaPS) Program, Management Sciences for Health, Arlington, VA, USA

Full list of author information is available at the end of the article
}

chronic respiratory infections, hypertension, and diabetes are responsible for more than 32 million deaths per year in LMICs [2]. Global health programmes and partnerships such as the Global Fund and The President's Emergency Plan for AIDS Relief (PEPFAR) have been tremendously successful in mobilising resources and scaling up treatment for communicable diseases [3-6]. However, these initiatives are unsustainable in the absence of donor support and insufficient for tackling the challenges that come with the triple transition. The need to respond to emergency public health challenges such as HIV, TB, and malaria has led to an undue emphasis on the supply chains that deliver commodities required for the diagnosis and treatment of these diseases. 
Many of the challenges that remain in ensuring a population's access to and appropriate use of medicines and services, particularly in the context of the health-related SDGs, require pharmaceutical systems strengthening approaches. This goes beyond the narrow focus of avoiding stockouts of a subset of health products. Pharmaceutical systems strengthening recognises the various structures, processes, and their interactions within the broader health system that help to ensure access to and appropriate use of safe, effective, quality medicines [7]. However, acknowledging the centrality of pharmaceutical systems strengthening and incorporating it into the current global health scenario require recognition of a few interrelated and 'uncomfortable truths'.

\section{Three truths}

First, pharmaceutical systems strengthening is a lengthy and resource-intensive process that may not align with the short time frame for achieving targets in donorfunded programmes. For example, medicines and medical device registration is normally performed by a national regulatory agency before products can be used in the country. Many national regulatory agencies, especially in LMICs, face significant challenges, including inadequate funding, human resources, regulatory capacity and subject matter expertise, the fragmentation of regulatory functions, critical human resource shortages, and lack of sustainable funding. As a result of this systemic weakness, medicines registration decisions in many LMICs can be unnecessarily prolonged and burdensome. Global health programmes usually rely on stringent regulatory authorities or the World Health Organization (WHO) prequalification programme to assure the quality of the products they are purchasing. This approach, along with special WHO programmes to expedite national registration based on WHO prequalification, successfully addresses the short-term goal of making products procured by global health programmes quickly available to address urgent needs [8]. However, strengthening national regulatory capacity to ensure that all medical products circulating in a country are safe, effective, and quality assured requires a much longer time commitment and more resources.

Second, pharmaceutical systems strengthening includes strengthening governance through interventions such as the reform of policies and legislation; creation of organisational structures for appropriate decision making, authority, and oversight; and incorporating tenets of good governance (such as transparency, accountability and civil society participation) in systems and processes [9]. Such interventions require country ownership and sustained engagement with multiple stakeholders, some of whom are beyond the immediate health sector. For example, sustained engagement with multiple stakeholders including the ministries of health, justice and agriculture, private sector pharmacy groups and universities has proven critical for building political will and maintaining momentum during the protracted legislative reform needed in instances such as providing the necessary legal mandate for establishing a medicines regulatory authority or requiring the use of the national essential medicines list as the sole list for public procurement [9]. And yet, attempts to integrate diseasespecific programmes into national health systems often have insufficient effort focused on national ownership, stewardship, and other health system functions [10-12]. Further, to the extent that other health system functions are considered, their importance is often limited to how well they facilitate the achievement of specific programme targets.

Third, it is not clear what systems strengthening interventions work and why. A variety of tools exist to assess health systems [13-15], and recent efforts have sought to document the outcomes and impacts of systems strengthening interventions on health [16-18]. However, there is a lack of clarity on what key metrics associated with population and patient-level outcomes should be tracked to evaluate pharmaceutical systems strengthening interventions. On the other hand, disease-specific programmes have been tracking population outcomes to allow for effective communication and advocacy and resonance with decision makers. We know, for example, that the Global Fund has saved 32 million lives as of the end of 2018, and that overall, the number of deaths caused by AIDS, TB, and malaria each year has decreased by $40 \%$ since 2002 in countries where the Global Fund invests [4]. The lack of consensus on reliable measures for evaluating pharmaceutical systems strengthening efforts limits the ability to make persuasive investment cases for national governments and donors, who need robust evidence for decision-making and optimizing the allocation of limited resources. The WHO Global Benchmarking Tool for evaluation of national regulatory systems (GBT) and the WHO Joint External Evaluation tool are two globally accepted tools that could serve as models for a possible approach to measurement and incentivizing countries to assess their pharmaceutical systems. WHO recently finalised the GBT, which is the first internationally agreed-upon tool for objectively assessing the functionality and capacities of national medicines regulatory systems and creating an institutional development plan for countries. Similarly, the WHO Joint External Evaluation tool assesses countries' ability to prepare for and respond to infectious disease risks and prioritizes areas for improvement. The multisectoral approaches of the WHO Joint External Evaluations and heavy reliance on multi-stakeholder engagement could also provide lessons for sustaining 
stakeholder engagement and multisectoral coordination, which is critical given the multisectoral approaches required for the SDGs.

\section{Conclusion}

Public health challenges such as HIV and TB, and more recently emerging threats such as COVID-19 have underscored the need for resilient health systems in mounting an effective public health response. Moving forward, it is important to find ways to balance the inherent tensions between the short-term focus on the efficiency of disease-specific programmes and broader, longer-term health and development objectives that require high-performing, sustainable health systems. This will also require a shift away from viewing medicines solely as an input commodity, or supply chain management concern, to a more holistic and comprehensive view that recognizes the various structures, processes and their interactions within the broader health system that help ensure access to and appropriate use of medicines and related services. It is also important to build the evidence base and agree on the metrics for evaluating the effectiveness of pharmaceutical systems strengthening interventions with respect to health and population outcomes. This requires implementation research to identify effective interventions and better understand what approaches work and why, which can then inform policy advocacy and action. Globally agreed-upon measures and benchmarks could also provide incentives for standardising country-level measures and for countries to use them to monitor and strengthen their systems.

\section{Abbreviations}

GBT: WHO Global Benchmarking Tool for evaluation of national regulatory systems; LMICs: Low- and middle-income countries; PEPFAR: The President's Emergency Plan for AIDS Relief; SDG: Sustainable Development Goals; UHC: Universal health coverage; WHO: World Health Organization

\section{Acknowledgements}

The authors thank Nicole Barcikowski, Tobey Busch, Mimi Darko, Niranjan Konduri, Alexis Leonard, Lisa Ludeman, and Helena Walkowiak for their review of earlier drafts.

\section{Authors' contributions}

$J G$ conceived the initial idea and all authors contributed to the final conceptualization. TH drafted and finalized the manuscript. All authors reviewed and contributed substantively to revisions of the manuscript. All authors read and approved the final manuscript.

\section{Authors' information}

Tamara Hafner, PhD, Principal Technical Advisor, USAID Medicines, Technologies, and Pharmaceutical Services (MTaPS) Program, Management Sciences for Health, Virginia, USA.

Marlon Banda, Chief of Pharmacy Services \& Logistics of the Churches Health Association of Zambia, Lusaka, Zambia.

Jillian Kohler, PhD, Professor, Leslie Dan Faculty of Pharmacy \& Dalla Lana School of Public Health \& Munk School of Global Affairs \& Public Policy, University of Toronto. Director, WHO Collaborating Centre for Governance, Transparency \& Accountability in the Pharmaceutical Sector, Toronto, Canada.
Zaheer-Ud-Din Babar, BPharm MPharm PhD SFHEA is Professor in Medicines and Healthcare and Director of Pharmaceutical Policy and Practice Research Centre at the Department of Pharmacy, University of Huddersfield, United Kingdom.

Murray Lumpkin, MD MSc, Deputy Director, Integrated Development, Lead for Global Regulatory Systems Initiatives, Bill and Melinda Gates Foundation, Bill and Melinda Gates Foundation, Seattle, USA, Murray.

Lumpkin@gatesfoundation.org

Mojisola Christianah Adeyeye, PhD, Director-General of the National Agency for Food and Drug Administration and Control, Abuja, Nigeria.

Emmanuel Nfor, Deputy Technical Director, USAID Medicines, Technologies, and Pharmaceutical Services (MTaPS) Program, Management Sciences for Health, Arlington, Virginia, USA.

Francis Aboagye-Nyame, B. Pharm (Hons) MSc MBA MPSGh FGCPharm FPCPharm, Program Director, USAID Medicines, Technologies, and Pharmaceutical Services (MTaPS) Program, Management Sciences for Health, Arlington, Virginia, USA.

Javier Guzman, MD MSc, Technical Director at the USAID Medicines, Technologies, and Pharmaceutical Services (MTaPS) Program, implemented by Management Sciences for Health, Virginia, USA.

\section{Funding}

This work is made possible by the generous support of the US Agency for International Development (USAID) under contract no. (7200AA18C00074). The contents are the responsibility of the authors and do not necessarily reflect the views of USAID or the US Government.

The views expressed herein reflect those of the authors in their personal capacity, and in no way reflect the views of the organizations with which they are affiliated.

\section{Availability of data and materials \\ Not applicable.}

\section{Ethics approval and consent to participate}

Not applicable.

\section{Consent for publication}

All authors approved the manuscript.

\section{Competing interests}

ZUDB is the Editor in Chief of Journal of Pharmaceutical Policy and Practice. The other authors declare no competing interests.

\section{Author details}

${ }^{1}$ USAID Medicines, Technologies, and Pharmaceutical Services (MTaPS) Program, Management Sciences for Health, Arlington, VA, USA. ${ }^{2}$ Churches Health Association of Zambia, Lusaka, Zambia. ${ }^{3}$ Leslie Dan Faculty of Pharmacy \& Dalla Lana School of Public Health \& Munk School of Global Affairs \& Public Policy, University of Toronto, Toronto, ON, Canada. ${ }^{4}$ Department of Pharmacy, University of Huddersfield, Queensgate, Huddersfield HD1 3DH, UK. ${ }^{5}$ Bill and Melinda Gates Foundation, Seattle, WA, USA. ${ }^{6}$ National Agency for Food and Drug Administration and Control, Abuja, Nigeria.

Published online: 25 June 2020

\section{References}

1. Silverman R, Keller J, Glassman A, Chalkidou K. Tackling the triple transition in global health procurement. Washington DC: Center for Global Development; 2019. https://www.cgdev.org/sites/default/files/better-healthprocurement-tackling-triple-transition.pdf. Accessed 20 Feb 2020.

2. Bennett JE, Stevens GA, Mathers CD, Bonita R, Rehm J, Kruk ME, Riley LM, Dain K, Kengne AP, Chalkidou K, Beagley J. NCD countdown 2030: worldwide trends in non-communicable disease mortality and progress towards sustainable development goal target 3.4. Lancet. 2018;392(10152): 1072-88.

3. Bekker LG, Alleyne G, Baral S, Cepeda J, Daskalakis D, Dowdy D, Dybul M, Eholie S, Esom K, Garnett G, Grimsrud A. Advancing global health and strengthening the HIV response in the era of the sustainable development goals: the international AIDS society-lancet commission. Lancet. 2018; 392(10144):312-58. 
4. The Global Fund. Results report 2019. Geneva: The Global Fund; 2019. https://www.theglobalfund.org/media/8752/corporate_2019resultsreport_ report_en.pdf?u=637146355110000000. Accessed 20 Feb 2020.

5. Ikilezi G, Augusto OJ, Dieleman JL, Sherr K, Lim SS. Effect of donor funding for immunization from Gavi and other development assistance channels on vaccine coverage: evidence from 120 low and middle income recipient countries. Vaccine. 2020;38(3):588-96.

6. Jaupart P, Dipple L, Dercon S. Has Gavi lived up to its promise? Quasiexperimental evidence on country immunisation rates and child mortality. BMJ Glob Health. 2019;4(6):e001789.

7. Hafner T, Walkowiak H, Lee D, Aboagye-Nyame F. Defining pharmaceutical systems strengthening: concepts to enable measurement. Health Policy Plan. 2017;32(4):572-84.

8. Chahal HS, Koukounas K, Capella P, Presto R, Murray JS, Shimer M, Riley K, Valdez ML. An evaluation of US Food and Drug Administration's program to register HIV drugs for use in resource-constrained settings. JAMA Netw Open. 2019;2(11):e1915787.

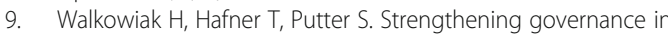
pharmaceutical systems: a compendium of country case studies. Arlington VA: Submitted to the US Agency for International Development by the Systems for Improved Access to Pharmaceuticals and Services (SIAPS) Program. Management Sciences for Health; 2018. http://siapsprogram.org/ wp-content/uploads/2018/03/18-054-SIAPS-GovCase-Study-Compendium_ FINAL.pdf. Accessed 20 Feb 2020.

10. Bowser D, Sparkes SP, Mitchell A, Bossert TJ, Bärnighausen T, Gedik G, Atun R. Global Fund investments in human resources for health: innovation and missed opportunities for health systems strengthening. Health Policy Plan. 2014;29(8):986-97.

11. Hope R, Kendall T, Langer A, Bärnighausen T. Health systems integration of sexual and reproductive health and HIV services in sub-Saharan Africa: a scoping study. J Acquire Immune Defic Syndr. 2014;67(Suppl 4):S259.

12. Mwisongo A, Nabyonga-Orem J. Global health initiatives in Africagovernance, priorities, harmonisation and alignment. BMC Health Serv Res. 2016;16(4):212.

13. Aqil A, Silvestre E, Hotchkiss D, Maniscalco L. Health systems strengthening: monitoring, evaluation, and learning guide. Chapel Hill, NC: MEASURE Evaluation; 2017. https://www.measureevaluation.org/resources/ publications/tr-17-167c. Accessed 20 Feb 2020.

14. Health Finance \& Governance Project. Health systems assessment approach a how-to manual. Version 3.0. Bethesda, MD: Health Finance \& Governance Project, Abt Associates Inc; 2017. https://www.hfgproject.org/the-healthsystem-assessment-approach-a-how-to-manual/. Accessed 20 Feb 2020.

15. World Health Organization. Monitoring the building blocks of health systems: a handbook of indicators and their measurement strategies. Geneva: World Health Organization; 2010. https://www.who.int/healthinfo/ systems/WHO_MBHSS_2010_full_web.pdf?ua=1. Accessed 20 Feb 2020 .

16. Hatt L, Johns B, Connor C, Meline M, Kukla M, Moat K. Impact of health systems strengthening on health. Bethesda, MD: Health Finance \& Governance Project, Abt Associates; 2015. https://www.hfgproject.org/ impact-hss-health/. Accessed 20 Feb 2020

17. Koon AD, Conrad A, Naimoli JF, Saxena S, Connor C, Rodriguez DC. Implementing health system strengthening projects at USAID: findings from five cases using an integrated framework. Global Public Health. 2019;14(12): $1829-46$.

18. Witter S, Palmer N, Balabanova D, Mounier-Jack S, Martineau T, Klicpera A, Jensen C, Pugliese-Garcia M, Gilson L. Health system strengthening - reflections on its meaning, assessment, and our state of knowledge. Int J Health Plann Manag. 2019;34(4):e1980-9.

\section{Publisher's Note}

Springer Nature remains neutral with regard to jurisdictional claims in published maps and institutional affiliations.

Ready to submit your research? Choose BMC and benefit from:

- fast, convenient online submission

- thorough peer review by experienced researchers in your field

- rapid publication on acceptance

- support for research data, including large and complex data types

- gold Open Access which fosters wider collaboration and increased citations

- maximum visibility for your research: over $100 \mathrm{M}$ website views per year

At $\mathrm{BMC}$, research is always in progress.

Learn more biomedcentral.com/submissions 